\title{
Reversal of Renal Tubule Transporter Downregulation during Severe Leptospirosis with Antimicrobial Therapy
}

\author{
Anne Spichler,* Albert I. Ko, Everton Fagonde Silva, Thales De Brito, Ana Maria Silva, Daniel Athanazio, \\ Cleiton Silva, and Antonio Seguro \\ Department of Nephrology, LIM 12, University of São Paulo School of Medicine, São Paulo, Brazil; Gonçalo Moniz Research \\ Centre, Oswaldo Cruz Foundation, Salvador, Brazilian Ministry of Health, Salvador, Brazil; Division of International Medicine and \\ Infectious Disease, Weill Medical College of Cornell University, New York; Biotechnology Centre, Federal University of \\ Pelotas, Pelotas, Brazil; Institute of Tropical Medicine, University of São Paulo, São Paulo, Brazil; Department of Biointeraction, \\ Federal University of Bahia, Health Sciences Institute, Salvador, Brazil
}

\begin{abstract}
Tubular dysfunction is a hallmark of severe leptospirosis. Antimicrobial therapy is thought to interfere on renal involvement. We evaluated the expression of a proximal tubule type-3 $\mathrm{Na}^{+} / \mathrm{H}^{+}$exchanger (NHE3) and a thick ascending limb $\mathrm{Na}^{+}-\mathrm{K}^{+}-2 \mathrm{Cl}^{-}$co-transporter $(\mathrm{NKCC} 2)$ in controls and treated hamsters. Animals infected by a serovar Copenhageni isolate, were treated or not with ampicillin (AMP) and/or $N$-acetylcysteine (NAC). Leptospiral antigen(s) and expression of renal transporters were evaluated by immunohistochemistry, and serum thiobarbituric acid (TBARS) was quantified. Infected hamsters had high amounts of detectable leptospiral antigen(s) in target tissues while renal expression of NHE3 and NKCC2 decreased. Ampicillin treatment was associated with minimal or no detection of leptospiral antigens, normal expression of NHE3 and NKCC2 transporters, and reduced levels of TBARS. NAC effect was restricted to lowering TBARS. Early and late AMP treatment rescued tubular defects in severe leptospirosis disease, and there was no evidence of benefit from antioxidant therapy.
\end{abstract}

\section{INTRODUCTION}

Leptospirosis is a zoonosis of worldwide distribution. ${ }^{1,2}$ About $5-10 \%$ of all human infections occur with severe forms. Weil's syndrome, the most common presentation of severe forms of leptospirosis, may present either as a biphasic or as a single monophasic disease characterized by a combination of hemorrhage, particularly in the lung, renal failure, and jaundice, with fatality rates ranging from $55 \%$ to $25 \% .^{1,3,4}$ Hamsters and guinea pigs reproduce both severe forms of leptospirosis under experimental conditions. ${ }^{5-7}$

The kidney is an important target organ in leptospiral infection. ${ }^{8-10}$ Clinically, renal involvement in leptospirosis occurs in $16-40 \%$ of cases and is unique because of the atypical presentation of polyuria, hypokalemia, and sodium and potassium wasting. ${ }^{9,11,12}$ Severe renal dysfunction progresses to dehydration, hyperkalemia and oliguria, paralleled by acute tubular necrosis, and predicts higher lethality. ${ }^{13,14}$ The pathogenesis may be related to direct toxic effects of leptospiral compounds on renal transporters and microcirculation or to indirect effects of the pro-inflammatory response, with severe tissue damage due to oxidative stress. ${ }^{15-17} \mathrm{~N}$-Acetylcysteine, an antioxidant, scavenger of reactive oxygen species, could be considered for adjunctive therapy in this disease, as it interferes with the oxidative effects of inflammation. ${ }^{18}$

The postulated targets of tubular dysfunction in leptospirosis are related to the major sodium transporters expressed along the nephron. ${ }^{19-21}$ The type-3 $\mathrm{Na}^{+} / \mathrm{H}^{+}$exchanger (NHE3) provides the major route for sodium transport across the apical membrane of the proximal tubule. The $\mathrm{Na}^{+}-\mathrm{K}^{+}-\mathrm{Cl}^{-}$ co-transporter ( $\mathrm{NKCC} 2)$ plays a role in the regulation of water excretion and fine control of sodium balance in the thick ascending limb (TAL), ${ }^{22-24}$ and $\mathrm{Na}^{+} / \mathrm{K}^{+}$-ATPase participates

\footnotetext{
* Address correspondence to Anne Spichler, University of São Paulo, Department of Nephrology, Laboratorio Pesquisa Basica LIM/12, Faculdade de Medicina USP, Av. Dr. Arnaldo, $4553^{\circ}$ Andar, Sala 3310, CEP 01246-903 São Paulo, SP, Brazil. E-mail: annespichler@ terra.com.br
}

in the sodium and potassium balance. ${ }^{25}$ During leptospiral infection, lesions involves the proximal tubules, with leptospiral antigens shown mainly in that segment. ${ }^{10}$ Previous experiments showed a downregulation of NKCC2 co-transporter activity, in TAL segments during leptospiral infection. ${ }^{19}$

A wide range of antimicrobial therapy for leptospirosis has been described in human and experimental studies, ${ }^{26-29}$ and benefits have been disputed for cases with $>4$ days of clinical disease. ${ }^{30,31}$ There is also evidence that, after a threshold of leptospiremia, the delayed use of antibiotics is unlikely to reduce lethality. ${ }^{32,33}$ Supportive treatment of renal failure is crucial in clinical management with a major impact on fatality. ${ }^{13,14}$ A limited number of specialized studies have focused on the molecular basis of ionic transport dysfunction in kidneys among patients with severe leptospirosis, ${ }^{19}$ but no reports have yet evaluated the impact of antibiotics on their expression.

The present study addresses therapeutic removal of leptospires from infected target tissues, its importance on the baseline expression of NHE3 and NKCC2 in infected hamsters reproducing the two forms of clinical presentations of Weil's syndrome. We also propose to determine the levels of systemic markers of oxidative stress in the same model and the effect of $N$-acetylcysteine (NAC) as adjunct therapy.

\section{MATERIALS AND METHODS}

Leptospira. Leptospira interrogans serovar Copenhageni strain FIOCRUZ L1-130 was originally isolated from a patient with severe leptospirosis during an epidemic outbreak in 1996. ${ }^{34}$ The strain was passaged and re-isolated four times from hamsters after isolation from a blood culture from the patient and stored at $-70^{\circ} \mathrm{C}$. Frozen aliquots were thawed and passaged in liquid medium seven times prior its use as a lowpassage-number isolate. Leptospires were cultivated in liquid Ellinghausen-McCullough-Johnson-Harris (EMJH) medium (Difco Laboratories, Detroit, MI) at $29^{\circ} \mathrm{C}$, and counted in a Petroff-Hausser counting chamber by darkfield microscopy (Fisher Scientific, Pittsburgh, PA). 
Animals. Female golden Syrian hamsters weighing 80-85 g (Fiocruz-Bahia), were maintained under conventional environmental conditions and observed twice daily. Animals were inoculated intraperitoneally with $1 \mathrm{~mL}$ of EMJH medium (Difco Laboratories) adjusted to obtain $10^{8}$ leptospires in Experiment 1 (E1) and $10^{3}$ in Experiment 2 (E2).

Both experiments intended to reproduce two clinical forms of Weil's diseases: E1, the acute monophasic progressive illness, and E2, a prolonged course of infection. Animals were euthanized with sodium thiopental at defined dates. At necropsy, blood and target organs (kidney, lung, and liver) were collected for serum and histopathology analysis respectively. All experiments were approved by the Institutional Animal Care and Use Committee.

Experimental design. In E1, animals were injected with $10^{8}$ leptospires and received no treatment (infected-untreated group). The AMP-treated group was infected with the same inoculum and received AMP subcutaneously, $100 \mathrm{mg} / \mathrm{kg} /$ day bid (AMP group). The NAC-treated group received a NAC dose of $100 \mathrm{mg} / \mathrm{kg} / \mathrm{bid}$ intraperitoneally (NAC group). The AMP plus NAC group was treated with both drugs (AMP+NAC group). Therapy was started after clinical detection of fever, prostration, and piloerection. Animals were killed on the fifth day based on previous pilot experiments which identified this as the probable date of death for hamsters infected with the same strain and inoculum. For each antimicrobial tested, the treated group included 6 animals per group. The untreated infection group was inoculated under the same conditions and included 6 animals per group.

In E2, animals were injected with $10^{3}$ leptospires and received no treatment (infected-untreated1 group). The AMPtreated group received AMP subcutaneously, $80 \mathrm{mg} / \mathrm{kg} /$ day bid (AMP1 group). The NAC-treated group received a dose of $100 \mathrm{mg} / \mathrm{kg} / \mathrm{bid}$ intraperitoneally (NAC1 group), and the AMP plus NAC group was treated with both drugs (AMP+NAC1 group). Each group included 6 animals. Therapy was started 6 days after infection and was continued for 4 days. Animals were killed on the tenth day, based on previous pilot experiments that identified this as the probable date of death for hamsters infected with the same strain and inoculum. The antimicrobial drugs were tested with lower dosage also in this experiment. Ampicillin subcutaneously, $80 \mathrm{mg} / \mathrm{kg} /$ day bid (AMP2 group), and AMP plus NAC (AMP+NAC2 group). Therapy was started 8 days after infection and was continued for 3 days. The animals were killed on the eleventh day. Each subgroup included 3 animals.

Previous observations indicated that both AMP doses were effective, ${ }^{28,29}$ but the different doses used were selected in an attempt to recapitulate two forms of treatment in Weil's syndrome. The higher inoculum presumably induces earlier symptoms and requires a higher antimicrobial dose, while the lower inoculum induces a longer preclinical interval and requires lower but also effective antibiotic doses.

Parallel to this study, non-infected hamsters were examined to verify baseline expression of NHE3 and NKCC2 on renal tissue.

Serum analysis. A product of lipid peroxidation and a marker of oxidative stress were determined by the thiobarbituric acid method as described elsewhere, ${ }^{35}$ while urea and bilirubin were determined by spectrophotometry.

Histology and immunohistochemistry (IHC) assay. Tissues (kidney, lung, and liver) from untreated and treated animals were fixed in $4 \%$ formalin, embedded in paraffin, cut into $3-\mu \mathrm{m}$ sections, and used for conventional histology (H\&E) and IHC to assess the presence of leptospiral antigen(s) (LAg). Immunohistochemistry was also performed to determine the expression of the renal sodium transporters NHE3 and $\mathrm{NKCC} 2$ in kidney tissue from infected untreated and treated animals as well as the baseline expression of noninfected hamsters.

IHC protocol for LAg. Immune serum was raised in rabbits according to a previously described standard procedure. ${ }^{36}$ Primary antibody titer was used at 1:7000 dilution. Kidney, liver, and lung 3- $\mu \mathrm{m}$ sections were analyzed using EnVision (DAKO code K4011) based on immunohistochemistry methods. $^{36}$

NHE3 and NKCC2 protocol. The sections were dewaxed and rehydrated, and the endogenous peroxidase was blocked by incubation with $3 \% \mathrm{H}_{2} \mathrm{O}_{2}$ in absolute methanol for $10 \mathrm{~min}$ at room temperature. Sections were then incubated with $1 \mathrm{M}$ Tris solution ( $\mathrm{pH}$ 9.0) supplemented with $0.5 \mathrm{mM}$ EDTA and heated using a microwave oven for 10 min to unmask antigen(s). Nonspecific binding of immunoglobulin was prevented by incubating the sections in $50 \mathrm{mM} \mathrm{NH}_{4} \mathrm{Cl}$ for $30 \mathrm{~min}$, followed by blocking in PBS supplemented with 1\% BSA, $0.05 \%$ saponin, and $0.2 \%$ gelatin. Sections were incubated overnight at $4{ }^{\circ} \mathrm{C}$ with primary antibodies diluted in PBS supplemented with $0.1 \%$ BSA and $0.3 \%$ Triton-X 100 .

Primary antibodies (rabbit polyclonal) NHE3 and NKCC2 were used in 1:100 and 1:50 dilutions respectively. ${ }^{37,38}$ Reactions were completed by incubating tissues with a dextran polymer (En Vision, DAKO code K4011). DAB was used to reveal the end products of the reactions.

Statistical analysis. Data are reported as mean \pm SD. The non-parametric Kruskal-Wallis test was used to compare serum marker measurements between groups.

Comparison between two independent groups was performed by the non-parametric Mann-Whitney test. Correlation coefficients between variables were determined by Spearman rank correlation. The level of significance was set at $P<0.05$ in all analyses. The SPSS package was used in this study (SPSS Inc., Chicago, IL).

\section{RESULTS}

Course of Weil's syndrome. In E1, in which antimicrobial treatment was programmed to start after the initial signs of Weil's syndrome, fever, prostration, and/or piloerection were observed 36 hours after infection. Hemorrhage, mainly in the nasal mucosa, was observed on the third day. In untreated animals, signs persisted until death, whereas AMP-treated animals showed no abnormalities until the day of sacrifice. All untreated animals developed clinical signs of disease, and half of them died before the fifth day.

In E2, the animals showed signs related to severe disease by the eighth day. Clinical signs were seen in $2 / 3$ of untreated and NAC-treated animals. Only one death each was observed in the AMP+NAC groups, on day 8 in the first group and on day 10 in the second group (Table 1).

Histopathology and immunohistochemistry (IHC) assay. Kidneys of infected animals were obtained from E1 (day 5) and E2 (days 10 and 11). The kidneys showed tubular necrosis in both experiments and evidence of focal interstitial nephritis in E2 (Figure 1). 
TABLE 1

Clinical signs and outcome of experimentally infected hamsters

\begin{tabular}{|c|c|c|c|c|c|c|}
\hline & $\begin{array}{l}\text { Fever } \\
n(\%)\end{array}$ & $\begin{array}{c}\text { Hemorrhage } \\
n(\%)\end{array}$ & $\begin{array}{c}\text { Prostration } \\
n(\%)\end{array}$ & $\begin{array}{l}\text { Jaundice } \\
n(\%)\end{array}$ & $\begin{array}{l}\text { Piloerection } \\
n(\%)\end{array}$ & $\begin{array}{l}\text { Death } \\
N(\%)\end{array}$ \\
\hline \multicolumn{7}{|l|}{ Experiment E1 } \\
\hline \multicolumn{7}{|l|}{ Groups $(N=6)$} \\
\hline UNTREATED & $4 / 6(67)$ & $2 / 6(33)$ & $6 / 6(100)$ & $2 / 6(33)$ & $2 / 6(33)$ & $3 / 6(50)$ \\
\hline AMP & - & - & - & - & - & - \\
\hline NAC & $2 / 6(33)$ & $3 / 6(50)$ & $5 / 6(84)$ & $2 / 6(33)$ & $2 / 6(33)$ & $3 / 6(50)$ \\
\hline $\mathrm{AMP}+\mathrm{NAC}$ & - & - & - & - & - & - \\
\hline \multicolumn{7}{|l|}{ Experiment E2 } \\
\hline \multicolumn{7}{|l|}{ Groups $(N=3)$} \\
\hline UNTREATED(1) & $1 / 3(33)$ & - & $1 / 3(33)$ & - & 2/3 (67) & - \\
\hline $\operatorname{AMP}(1)$ & - & - & - & - & - & - \\
\hline NAC(1) & $2 / 3(67)$ & - & $2 / 3(67)$ & - & 2/3 (67) & $\sim$ \\
\hline $\mathrm{AMP}+\mathrm{NAC}(1)$ & - & - & - & - & - & $1 / 3(33)$ \\
\hline $\operatorname{AMP}(2)$ & - & _- & $1 / 3(33)$ & - & $1 / 3(33)$ & $1 / 3(33)$ \\
\hline $\mathrm{AMP}+\mathrm{NAC}(2)$ & - & - & $1 / 3(33)$ & - & $1 / 3(33)$ & - \\
\hline
\end{tabular}
of E2; (2), second group of E2.

Persisting mild lesions or almost normal tissues were observed in animals treated with AMP in E1 and E2. IHC staining detected large amounts of leptospiral antigen(s) (LAg) in tubular cells, and this feature was more evident in E1. All of the AMP-treated animals of E1 and E2 showed lesser amounts or cleared LAg in kidney tissue (Figure 1). NAC did not induce any additional effect in either experiment.

Lung sections from the animals of both experiments revealed focal alveolar hemorrhage more prominent in E1 samples. Ampicillin-treated animals showed normal lung his- a
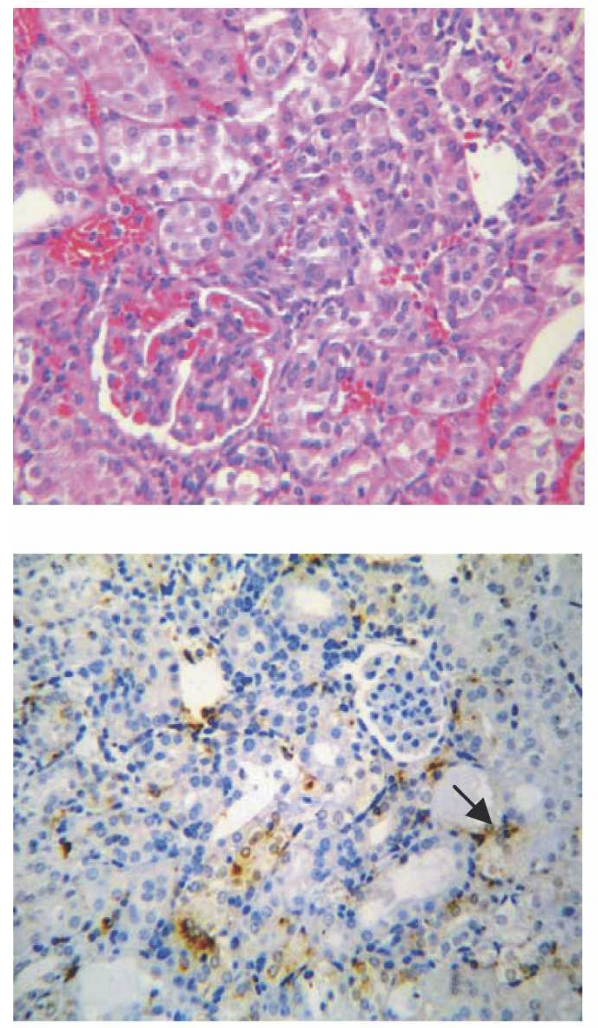

d

\section{b}
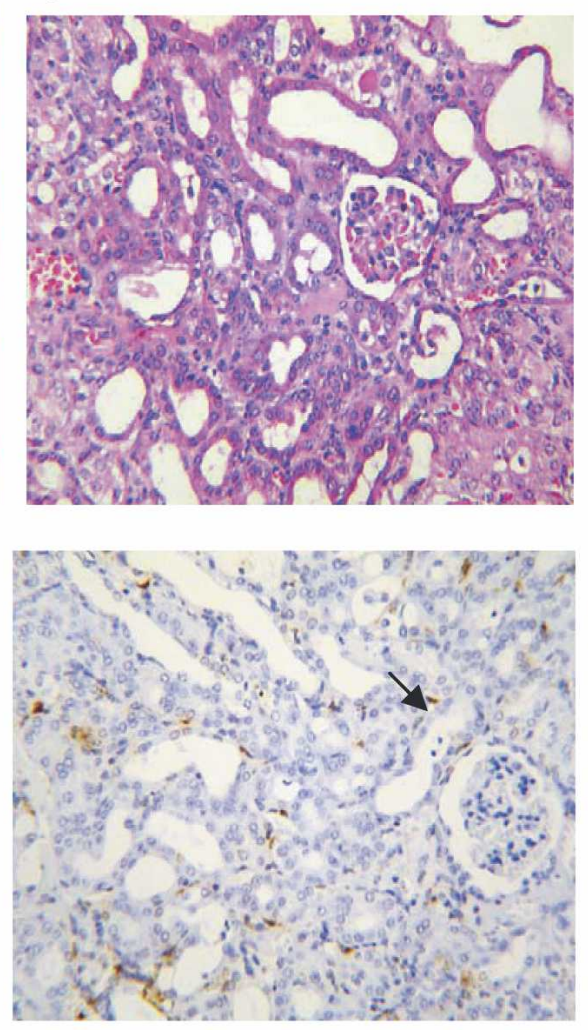

$\mathrm{e}$
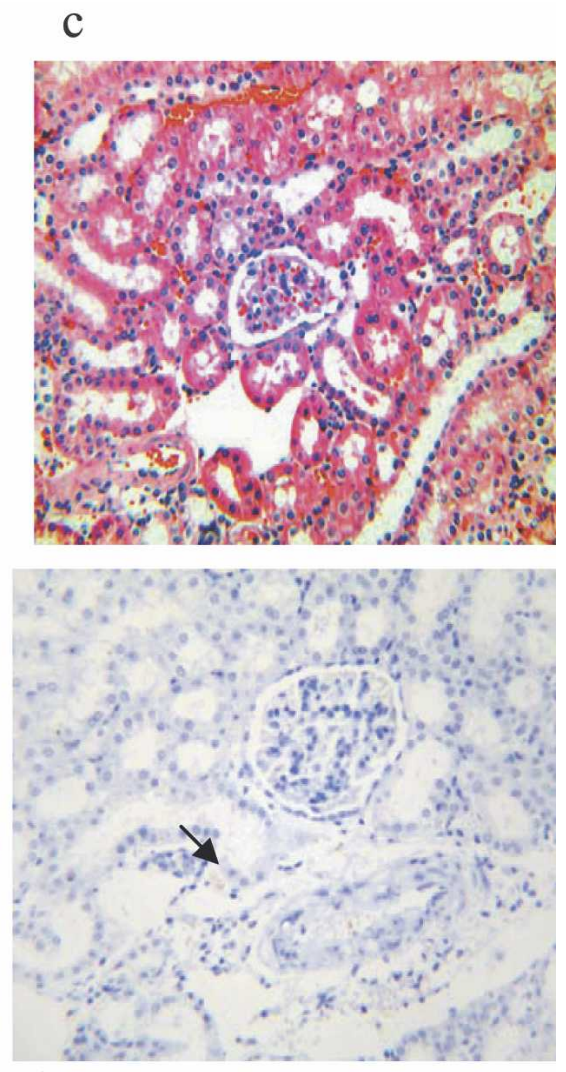

f

FiguRE 1. Histopathology of kidney tissue in infected and treated hamsters. (a, b) Kidney from infected, nontreated hamsters in E1 and E2, respectively. Note tubular cells with degenerative cytoplasmic alterations. (a) Dilated tubules with flat epithelial lining, interstitial inflammation, and edema; (b) H\&E, original magnification 200×; (c) renal tissue showing normal tubules in a treated animal in E1; H\&E, original magnification 200×. (d, e) IHC staining of renal tissue from infected, nontreated hamsters with LAg present in the cytoplasm of interstitial inflammatory cells in the kidney interstitium, prominent in (d) and (e). (f) LAg deposits are almost absent in treated animals in E2; original magnification 200×. This figure appears in color at www.ajtmh.org. 
tology. LAg could be detected in lung tissue but in smaller amounts when compared with other tissues. Treated animals showed a significant decrease of tissular LAg. No differences were observed in either experiment when NAC was added to the treatment (Figure 2).

Liver sections from the animals of both experiments revealed a typical picture of hepatocyte trabecular disarray and regenerative features. Ampicillin-treated animals showed normal appearing hepatic trabeculae. Similar to other tissues, only AMP treatment was associated with decreased amounts or clearance of LAg (Figure 3).

IHC demonstration of NHE3/NKCC2. The expression of NHE3 and NKCC2 in E1 and E2 was compared with that of normal, non-infected hamsters. In kidney tissues from E1 and E2, decreased or absent NHE3 activity was observed in the proximal tubules of infected hamsters, with the decrease being more marked in E1. In animals treated with AMP and $\mathrm{AMP}+\mathrm{NAC}$, anti-NHE3 antibody labeled the apical plasma membrane domains of the proximal tubules and showed increased activity compared with normal and infected animals (Figure 4). Similarly, IHC revealed a decrease in NKCC2 in the apical part of TAL cells of infected animals in both experiments, whereas an increase was observed in treated animals, especially in E1 (Figure 5). After antimicrobial treatment, and after Leptospira clearance, the expression of the transporters recovered.

A semiquantitative analysis from 0 (absent) to +++ (intense) was applied to verify LAg semiquantitative analysis and NHE3 and NKCC2 expression from all animals.
After they were killed, all of the animals showed LAg distribution on kidney, lung, and liver tissues. Animals that were treated with AMP and AMP+NAC demonstrated leptospiral decreased distribution, or clearance. Results of the kidney semiquantitative analysis of LAg and the NHE3 and NKCC2 expression from infected nontreated and AMP-treated animals in both experiments are in Table 2.

Serum analysis. In E1 and E2, the urea values of untreated controls were $412 \pm 150$ and $392.5 \pm 57 \mathrm{mg} / \mathrm{dL}$, respectively, being significantly higher than those of the AMP group (63 \pm 18 and $102 \pm 9 \mathrm{mg} / \mathrm{dL}$, respectively) and the AMP+NAC group (62 \pm 04 and $98 \pm 10 \mathrm{mg} / \mathrm{dL}$, respectively) $(P<0.005)$. There was no difference between the untreated and NAC groups.

In E1 and E2, the serum bilirubin values of untreated controls were $11.0 \pm 2.8$ and $17 \pm 3.5 \mathrm{mg} / \mathrm{dL}$, respectively, being significantly higher than those of the AMP group $[<1.0 \mathrm{mg} /$ $\mathrm{dL}(\mathrm{E} 1$ and E2)] and the AMP+NAC group $[<1.0 \mathrm{mg} / \mathrm{dL}(\mathrm{E} 1$ and E2)] $(P<0.005)$. There was no difference between the untreated and NAC groups.

In E1, in untreated control animals, serum TBARS levels were $17.6 \pm 7.2 \mu \mathrm{mol} / \mathrm{L}$, being significantly higher than those of the NAC $(3.2 \pm 1.7 \mu \mathrm{mol} / \mathrm{L}), \operatorname{AMP}(3.1 \pm 1.6 \mu \mathrm{mol} / \mathrm{L})$, and $\mathrm{AMP}+\mathrm{NAC}(2.1 \pm 1.2 \mu \mathrm{mol} / \mathrm{L})$ groups $(P<0.005)$.

\section{DISCUSSION}

In the present study, we were particularly interested in the effects of antibiotics and adjuvant antioxidant therapy on the a
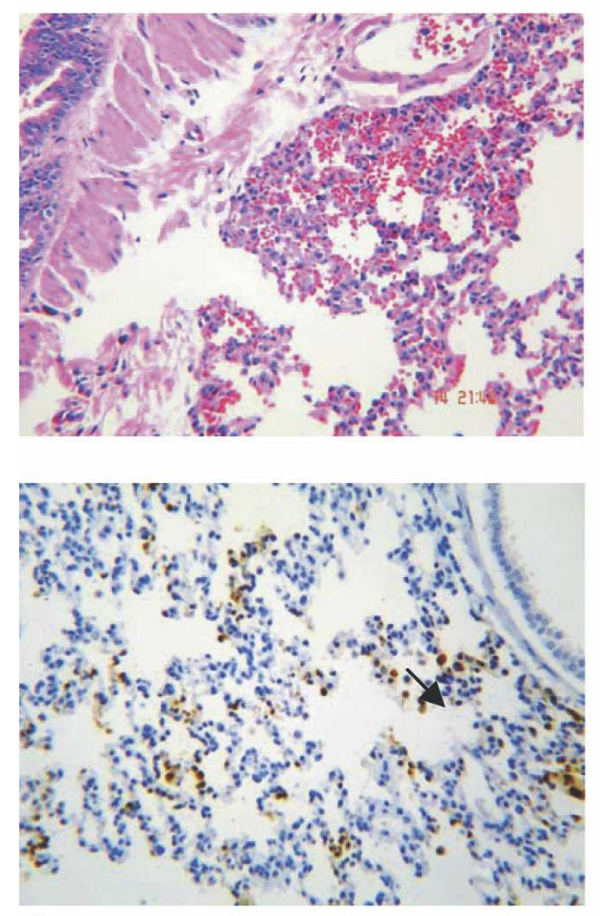

d b
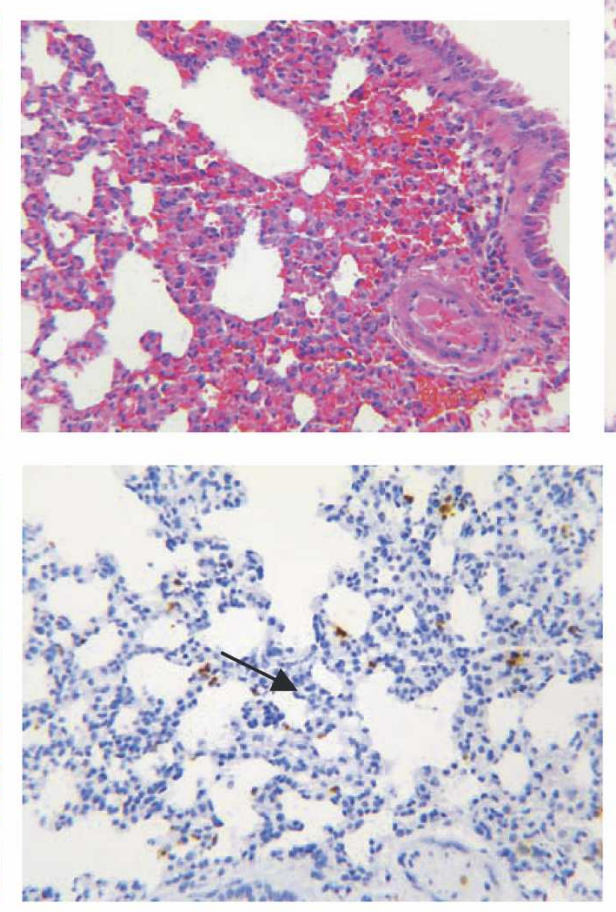

e
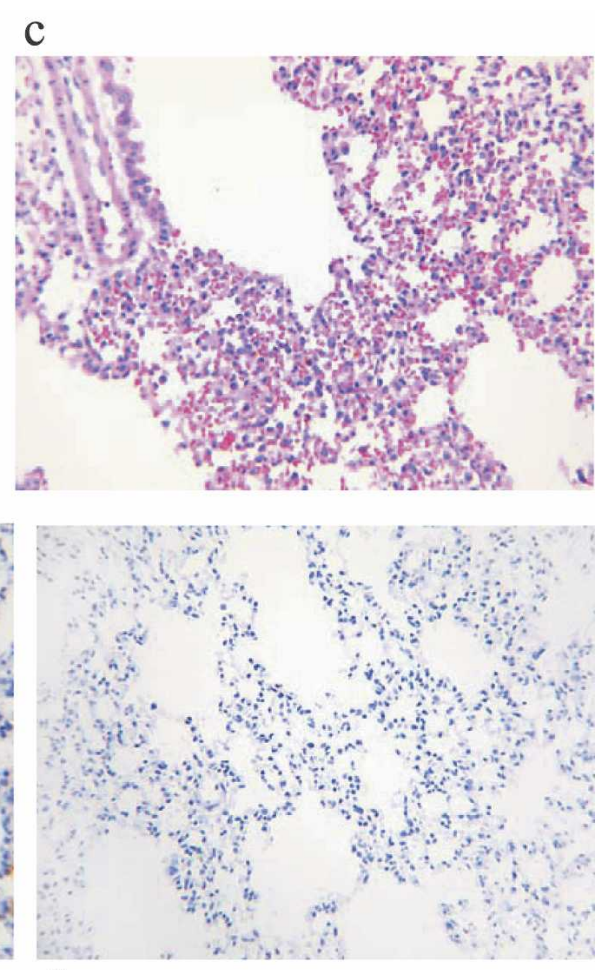

f

FiguRE 2. Histopathology of lung tissue in infected and treated hamsters. (a, b) Lung from infected, nontreated hamsters from E1 and E2, respectively. Focal pulmonary hemorrhage in lungs is more prominent in E1; H\&E, original magnification 200×. (c) Treated animals showed normal lung histology in E1; H\&E, original magnification 200×. (d, e) IHC-LAg deposits in lung from infected, nontreated hamsters are more evident in E1; original magnification 200×. (f) Absence of LAg deposits in treated animals in E2; original magnification 200×. This figure appears in color at www.ajtmh.org. 
a
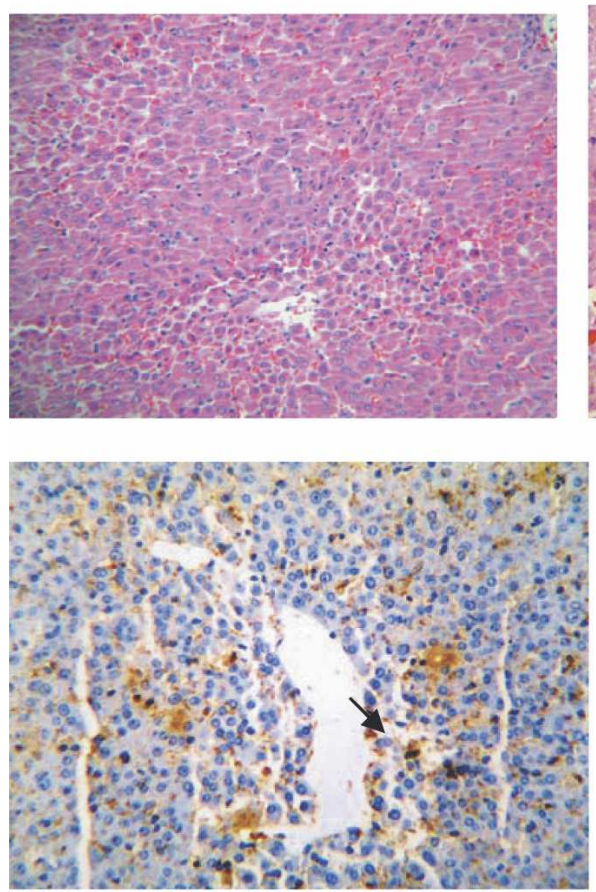

$\mathrm{c}$ b

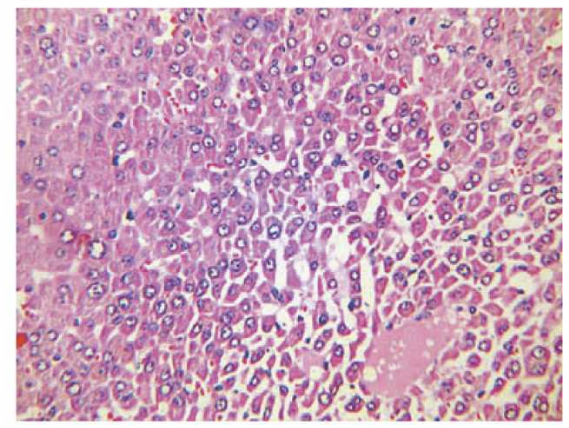

d

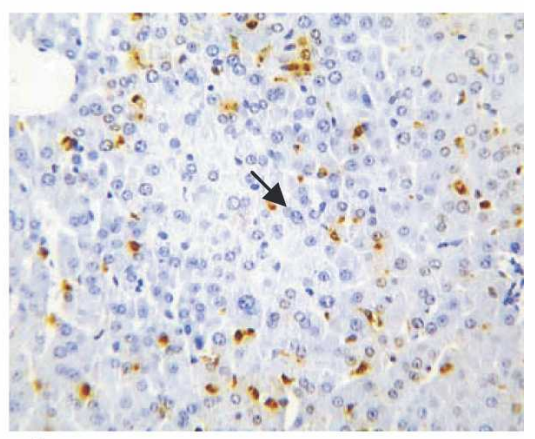

FIgURE 3. Histopathology of liver tissue from infected hamsters. (a, b) Liver from infected, non-treated hamsters from E1 and E2, showing liver plate disarray, particularly evident at the centrolobular region in both experiments; H\&E, original magnification 200×. (c, d) IHC-LAg in liver from infected, nontreated hamsters is more evident in E1; original magnification 200x. This figure appears in color at www.ajtmh.org.

NHE3 and NKCC2 renal transporters, which have been recently implicated in leptospiral acute renal failure. ${ }^{19,20}$

Two experiments simulating two clinical presentations of Weil's disease were designed: the high-inoculum experiment
(E1) was associated with earlier disease onset (fulminant monophasic illness) and higher amounts of leptospiral antigen(s) in tissues. The low-inoculum experiment (E2) was associated with prolonged disease (prolonged course of infec-

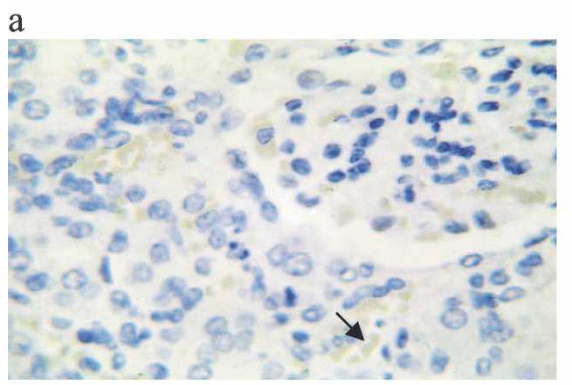

$\mathrm{b}$
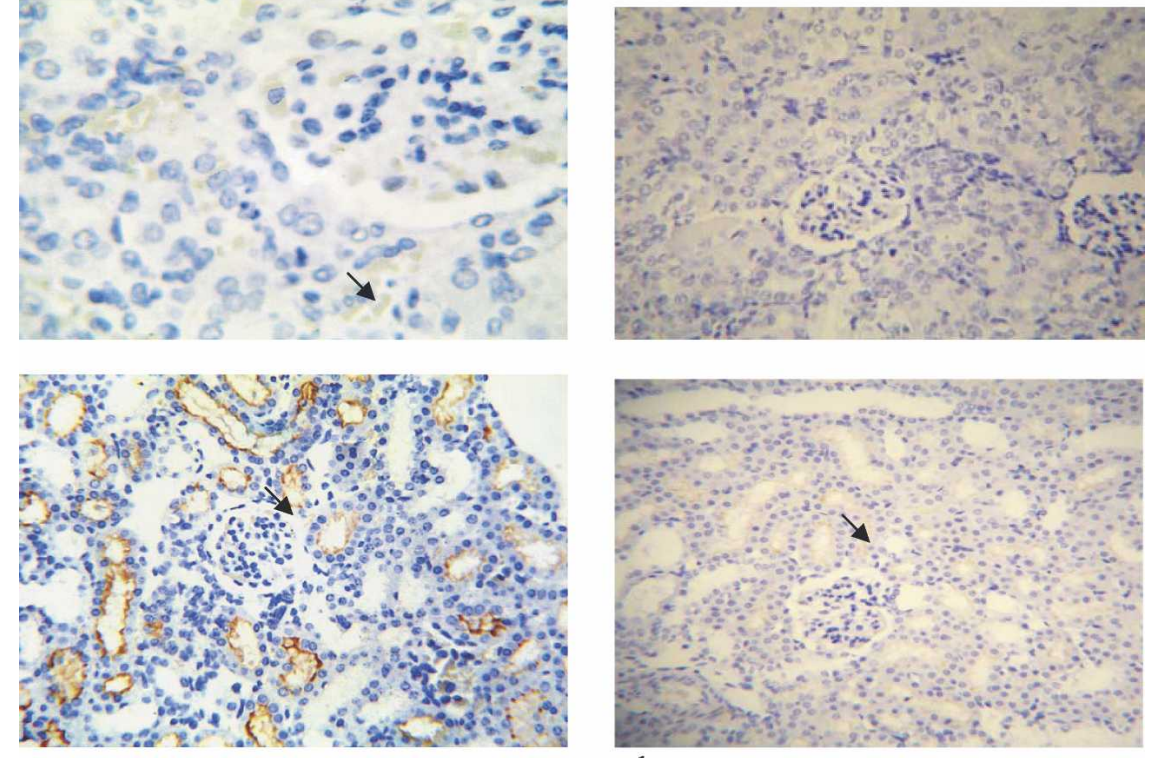

c

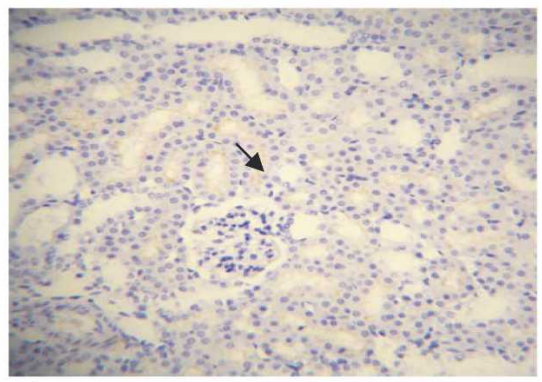

d

FIGURE 4. Immunohistochemical (IHC) analysis of NHE3 expression in proximal tubules. (a) Infected hamster in E1, showing decreased NHE3 in the apical domain of proximal tubule cells; original magnification 400×. (b) NHE3 is not expressed in infected hamsters in E2; original magnification 200×. (c) Treated animals in E1; NHE3 is clearly expressed. (d) Treated animals with AMP started 8 days after infection in E2; there was a light expression of NHE3; original magnification 200×. This figure appears in color at www.ajtmh.org. 
a
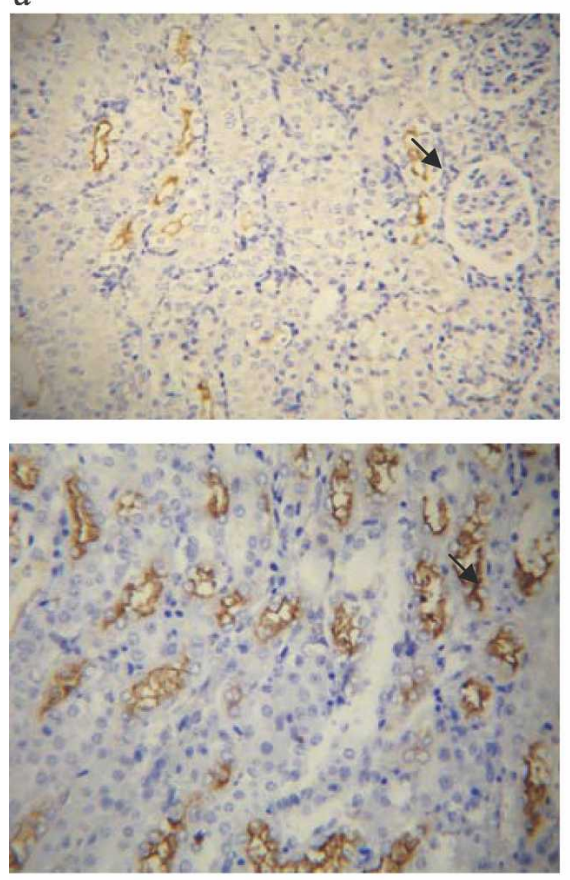

$\mathrm{c}$ b
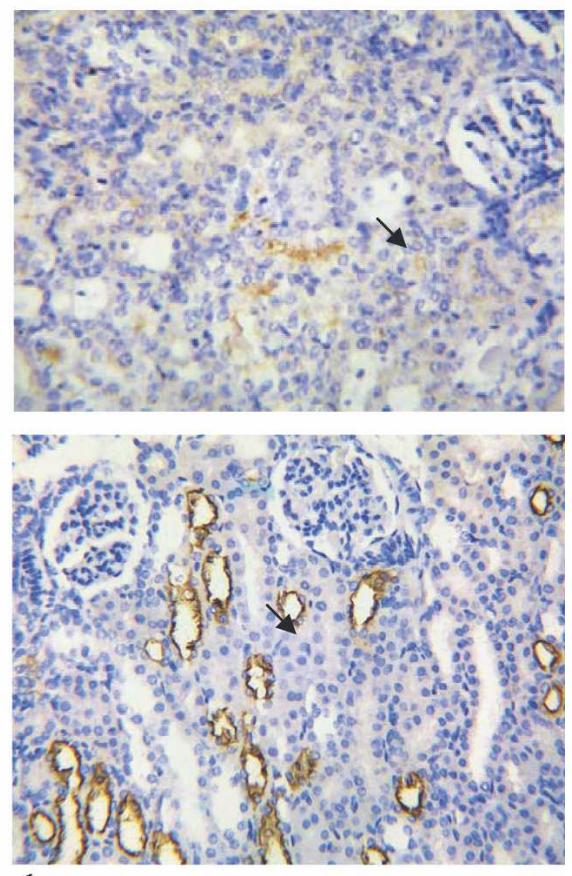

$\mathrm{d}$

FIGURE 5. IHC of NKCC2 expression in thick ascending limb. (a, b) Lower apical NKCC2 expression; original magnification 200× (a) and $360 \times(\mathbf{b})$. (c, d) Expression of NKCC2 in treated animals in E1 and E2 (treated animals with AMP started 8 days after infection); original magnification $360 \times(\mathbf{c})$ and $200 \times(\mathbf{d})$. This figure appears in color at www.ajtmh.org.

tion illness) and with the detection of lower amounts of LAg in target tissues.

Guinea pigs and hamsters are suitable experimental models for acute lethal leptospirosis. ${ }^{5-7}$ The spectrum of physiologic and morphologic lesions ranges from renal tubular and interstitial damage to pulmonary hemorrhages and jaundice, $, 39,40$ which were demonstrated in untreated infected hamsters in both experiments.

TABLE 2

A semiquantitative analysis to verify LAg, NHE3, and NKCC2 expression

\begin{tabular}{|c|c|c|c|c|c|c|c|}
\hline & Group & LAg in kidney tissue & NHE3 & $\mathrm{NKCC} 2$ & Signs of hemorrhage & Fever & Death \\
\hline \multicolumn{8}{|c|}{ Experiment 1 animals } \\
\hline G1A1 & UNTREATED & Not done & - & - & No & Yes & Yes \\
\hline G1A2 & & +++ & 0 & + & No & Yes & No \\
\hline G1A3 & & +++ & 0 & + & Yes & Yes & No \\
\hline G1A4 & & +++ & + & + & No & No & No \\
\hline G1A5 & & Not done & - & - & Yes & No & Yes \\
\hline G1A6 & & +++ & 0 & + & No & Yes & Yes \\
\hline \multicolumn{8}{|c|}{ Experiment 2 animals } \\
\hline G1A1 & UNTREATED & ++ & 0 & + & No & No & No \\
\hline G1A2 & & +++ & + & 0 & No & Yes & No \\
\hline G1A3 & & +++ & + & + & No & No & No \\
\hline \multicolumn{8}{|c|}{ Experiment 1 animals } \\
\hline G2A1 & AMP-treated & - & +++ & ++ & - & - & - \\
\hline G2A2 & & - & ++ & ++ & - & - & - \\
\hline G2A3 & & - & +++ & + & - & - & - \\
\hline G2A4 & & - & ++ & ++ & - & - & - \\
\hline G2A5 & & - & +++ & + & - & - & - \\
\hline G2A6 & & - & ++ & ++ & - & - & - \\
\hline \multicolumn{8}{|c|}{ Experiment 2 animals } \\
\hline $\mathrm{G} 2 \mathrm{~A} 1$ & AMP 1-treated & + & +++ & ++ & - & - & - \\
\hline G2A2 & & - & ++ & + & - & - & - \\
\hline G2A3 & & + & ++ & ++ & - & - & - \\
\hline G2A1 & AMP 2-treated & + & + & + & - & - & Yes \\
\hline $\mathrm{G} 2 \mathrm{~A} 2$ & & - & ++ & + & - & - & - \\
\hline G2A3 & & + & ++ & + & - & - & - \\
\hline
\end{tabular}

UNTREATED, untreated controls; AMP-treated, ampicillin-treated group from E1; AMP 1-treated, ampicillin-treated group from E2, started treatment on day 6 post-infection; AMP 2-treated, ampicillin-treated group from E2 started treatment on day 8 post-infection; LAg, leptospiral antigen. 
Blood urea has been previously used as a marker of renal failure in experimental leptospirosis, ${ }^{6,39}$ and also in our study infected animals presented a high serum urea levels. Blood samples obtained were too small to allow measurements of other biochemical parameters.

The two deaths seen in the treated groups probably indicate the limitation of antimicrobial therapy in the late stage of infection. ${ }^{41}$ Renal tubular lesions, focal alveolar hemorrhage, and liver plate disarray induced in the present animal model are the typical features of human and experimental leptospirosis. ${ }^{39,42-44}$ Identification of leptospira and/or their antigen(s) by IHC showed more LAg in kidney, liver, and lung in E1. The low amount of LAg detected in lung tissue is in accordance with previous findings. ${ }^{6,45,46}$

The effect of antimicrobial therapy for leptospirosis in clinical practice is a debated issue. Although most authors indicate the use of antibiotics irrespective of the duration of symptoms, ${ }^{26,47}$ available data from human disease and experimental models question the impact of antimicrobial therapy on late infection (after 4-5 days of symptoms). ${ }^{28,32,33}$ A wide range of antibiotics are effective against leptospires in vitro, in experimental animal models and in clinical trials. ${ }^{27-29}$ The probable explanation for the lack of impact of antimicrobial therapy on mortality in some instances is that, once they occur, renal and lung complications cannot be reversed by antibiotics and thus supportive care (peritoneal dialysis, mechanic ventilation) is an important tool to improve survival.

We believe these data are particularly important in the case of NHE3 and NKCC2 renal transporters because recent data have implicate direct toxic effects of leptospiral compounds on their inhibition. ${ }^{19}$

Ampicillin was selected because previous studies demonstrated benefits in vivo. ${ }^{28,29}$ Our choice to start antibiotics after the onset of clinical signs of leptospirosis in E1 and later in E2 better reflects the reality of clinical practice.

In both E1 and E2, treated hamsters presented significant decreased levels of systemic urea and bilirubin. Bilirubin is not directly related to renal failure, but when jaundice is present in Weil's disease, it increases morbidity and in some cases it has been used as a marker of disease severity. ${ }^{48}$ Histopathology of all treated animals in both experiments demonstrated a reduction or clearance of LAg and also a reduction of the most common lesions occurring in severe disease.

Leptospirosis is associated with peculiar defects in ionic transport along the nephron, resulting in excessive sodium and potassium wasting. ${ }^{9,10}$ Different mechanisms have been postulated and recent evidence points to inactivation and downregulation of NKCC2 in TAL cells or a toxic inhibition of $\mathrm{Na}^{+} / \mathrm{K}^{+}$-ATPase by leptospiral lipids. ${ }^{19,25}$ Recently, downregulation of NHE3 in renal proximal tubules was also demonstrated. $^{20}$

Previous studies have shown that the main factors associated with the pathogenesis of the disease are the presence of organisms and possibly the production of toxins. ${ }^{5,6}$ The proximal tubular location of leptospires and their products has been confirmed by some studies. ${ }^{6,15}$

$\mathrm{Wu}$ and others ${ }^{19}$ demonstrated the inhibitory effect of Leptospira santarosai serovar Shermani outer-membrane protein on NKCC2 in TAL cells. This inhibition results in more distal sodium delivery and subsequent renal potassium loss. Specific antiserum against the outer membrane protein of that lep- tospiral strain showed that inhibitory effects were partially abolished by antiserum. ${ }^{19}$ There is at least a direct effect from leptospira or leptospira compounds on renal transporters. In this experiment using an outer membrane protein from $L$. shermani, it inhibits $\mathrm{Na}^{+}-\mathrm{K}^{+}-\mathrm{Cl}^{-}$co-transporter (NKCC2) activity in medullary TAL cells, and these changes were dose dependent and reversed using antibody against outer membrane protein from $L$. shermani. In the same study, they suggested that cultured mTAL cells after 48 hours of incubation with $L$. shermani decreased NKCC2 activity and it was not related to cell damage. ${ }^{19}$

These experimental observations are in accordance with the physiologic characterization of ionic imbalance in patients with severe leptospirosis. ${ }^{19,21}$

In parallel to this study, we detected in both experiments a reduced NKCC2 expression in infected animals re-established after antimicrobial treatment. This was more striking in E1, but a limitation of the study was that quantification of renal transporter activity was not feasible. However, the differences between infected- untreated and treated hamsters, were evident. These results were similar to those observed for NHE3.

Andrade and others demonstrated inhibition of NHE3 activity, but increased NKCC2 activity in hamster with acute renal failure infected with serovar Pomona. ${ }^{20}$ The difference between our study and that of Andrade and others is that our model represents severe disease, with inocula of serovar Copenhageni producing more marked acute renal failure.

Because our model reproduced severe renal failure, it could temporarily affect these renal transporters. The present study did not focus on the primary event that triggers renal transporter dysfunction but did show that antibiotic therapy improves the expression of target molecules and renal function, as observed by serum urea measurements.

A role for systemic inflammation in leptospirosis is still disputed. A cross-sectional study on humans with severe disease demonstrated elevated serum markers of oxidative stress. ${ }^{17}$ A positive correlation between serum nitric oxide levels and creatinine in patients with acute severe leptospirosis was observed. ${ }^{49}$ Human and experimental studies using NAC demonstrated benefits against systemic inflammation and oxidative stress in different diseases and appeared to be a promising adjuvant therapy for malaria. ${ }^{50}$

In the present study, NAC decreased the serum levels of TBARS when administered alone to infected animals and had no beneficial effect on the histopathology or immunohistochemistry assays when administered alone or in combination with AMP.

The present study confirmed the reduced expression of NHE3 in the proximal tubules in a model of severe disease in both experiments, with expression being rescued by AMP treatment, probably due to leptospiral clearance. The same findings were observed for NKCC2 in TAL in both experiments. Our findings do not provide evidence of any benefit of antioxidant therapy in experimental leptospirosis. We suggest that tubular dysfunction in leptospirosis is probably related to direct effects of leptospires and/or their products on renal transporters and can be reversed by early and late antimicrobial therapy. This observation provides a further rationale to support the use of antibiotics in clinical practice even in late infection complicated by severe renal and respiratory disease.

Received March 13, 2007. Accepted for publication May 22, 2007. 
Financial support: Financial support for this study was provided by the Fundação de Amparo à Pesquisa do Estado de São Paulo, the Conselho Nacional de Desenvolvimento Científico e Tecnológico, the Fundação Faculdade de Medicina USP, and the Laboratório de Investigação Médica USP, and Public Health Service (grants AI052473 and TW00919), the National Institute of Allergy and Infectious Diseases (grants 300861/96-11 and 420067/2005-1), and the Renorbio Program from the Brazilian National Research Council.

Authors' addresses: Anne Spichler and Antonio Seguro, Department of Nephrology, LIM/12, University of São Paulo School of Medicine, and Laboratorio Pesquisa Basica LIM/12, Faculdade de Medicina USP, Av. Dr. Arnaldo, 455, 3rd floor, Room 3310, Mail code $01246-$ 903, São Paulo, Brazil, Telephone: +55 11 306209848, Fax: +55 11 30629848, E-mails: annespichler@terra.com.br and trulu@usp.br. Albert I. Ko, Everton Fagonde Silva, and Cleiton Silva, Centro de Pesquisas Gonçalo Moniz, Fundação Oswaldo Cruz/MS, Rua Waldemar Falcão, 121, Salvador, Bahia, Mail code 40295-001, Brazil, E-mails: aik2001@med.cornell.edu, efagonde@hotmail.com, and cleitonsilva@ hotmail.com. Thales De Brito and Ana Maria Silva, Institute of Tropical Medicine, University of Sao Paulo Medical School, LIM/06, Sao Paulo, Brazil, Telephone: +55-11-30617066, Fax: +55-1130645132, E-mail: thalesbr@usp.br. Daniel Athanazio, Departamento de Biointeração, ICS, UFBA, Av. Reitor Miguel Calmon, s/nº, Campus do Canela, Mail code 40.110-100, Salvador, Bahia, Brazil, E-mail: dathanazio@cpqgm.fiocruz.br.

\section{REFERENCES}

1. Bharti AR, Nally JE, Ricaldi JN, Matthias MA, Diaz MM, Lovett MA, Levett PN, Gilman RH, Willig MR, Gotuzzo E, Vinetz JM, 2003. Leptospirosis: a zoonotic disease of global importance. Lancet Infect Dis 3: 757-771.

2. Levett PN, 2001. Leptospirosis. Clin Microbiol Rev 14: 296-326.

3. Ricaldi J, Vinetz JM, 2006. Leptospirosis in the tropics and in travelers. Curr Infect Dis Rep 8: 51-58.

4. Spichler A, Moock M, Chapola EG, Vinetz JM, 2005. Weil's disease: an unusually fulminant presentation characterized by pulmonary hemorrhage and shock. Braz J Infect Dis 9: 336-340.

5. De Brito T, Freymuller E, Hoshino S, Penna DO, 1966. Pathology of the kidney and liver in the experimental leptospirosis of the guinea-pig. A light and electron microscopy study. Virchows Arch Pathol Anat Physiol Klin Med 341: 64-78.

6. Nally JE, Chantranuwat C, Wu XY, Fishbein MC, Pereira MM, Da Silva JJ, Blanco DR, Lovett MA, 2004. Alveolar septal deposition of immunoglobulin and complement parallels pulmonary hemorrhage in a guinea pig model of severe pulmonary leptospirosis. Am J Pathol 164: 1115-1127.

7. Oliva R, Infante JF, Gonzalez M, Perez V, Sifontes S, Marrero O, Valdes Y, Farinas M, Esteves L, Gonzalez I, 1994. Pathologicclinical characterization of leptospirosis in a golden Syrian hamster model. Arch Med Res 25: 165-170.

8. Seguro AC, Lomar AV, Rocha AS, 1990. Acute renal failure of leptospirosis: nonoliguric and hypokalemic forms. Nephron 55: $146-151$.

9. Yang CW, Wu MS, Pan MJ, 2001. Leptospirosis renal disease. Nephrol Dial Transplant 16: 73-77.

10. Sitprija V, Kearkiat P, 2005. Nephropathy in leptospirosis. J Postgrad Med 51: 184-188.

11. Abdulkader RCRM, Seguro A, Malheiro PS, Burdman EA, Marcondes M, 1996. Peculiar eletrolytic and hormonal abnormalities in acute renal failure due to Leptospirosis. Am J Trop Med Hyg 54: 1-6.

12. Covic A, Goldsmith DJ, Gusbeth-Tatomir P, Seica A, Covic M, 2003. A retrospective 5-year study in Moldova of acute renal failure due to leptospirosis: 58 cases and a review of the literature. Nephrol Dial Transplant 18: 1128-1134.

13. Marotto PCF, Nascimento CM, Eluf-Neto J, Marotto MS, Andrade L, Sztajnbok J, Seguro AC, 1999. Acute lung injury in leptospirosis: clinical and laboratory features, outcome, and factors associated with mortality. Clin Infect Dis 29: 1561-1563.

14. Sitiprija V, 2006. Renal Dysfunction in leptospirosis: a view from the tropics. Nat Clin Pract Nephrol 12: 658-659.

15. Barnett JK, Barnett D, Bolin CA, Summers TA, Wagar EA, Cheville NF, Hartskeerl RA, Haake DA, 1999. Expression and distribution of leptospiral outer membrane components during renal infection of hamsters. Infect Immun 67: 853-861.

16. Yang CW, Wu MS, Pan MJ, Hong JJ, Yu CC, Vandewalle A, Huang CC, 2000. Leptospira outer membrane protein activates $\mathrm{NF}-\kappa \mathrm{B}$ and downstream genes expressed in medullary thick ascending limb cells. J Am Soc Nephrol 11: 2017-2026.

17. Spichler A, Shimizu M, Seguro AC, 2005. Oxidative stress in leptospiroses: first report. In: Congresso da Sociedade Brasileira de Medicina Tropical: Encontro de Medicina Tropical do Cone Sul, 2005. Florianópolis: Revista da Sociedade Brasileira de Medicina Tropical, 459.

18. Zafarullah M, Li WQ, Ahmad M, 2003. Molecular mechanisms of $N$-acetylcysteine actions. Review. Cell Mol Life Sci 60: 6-20.

19. Wu M, Yang C, Pan M, Chang C, Chen Y, 2004. Reduced renal $\mathrm{Na}^{+}-\mathrm{K}^{+}-\mathrm{Cl}^{-}$co-transporter activity and inhibited NKCC2 mRNA expression by Leptospira shermani: from bed-side to bench. Nephrol Dial Transplant 19: 2472-2479.

20. Andrade L, Rodrigues AC Jr, Sanches TR, Souza RB, Seguro AC, 2007. Leptospirosis leads to dysregulation of sodium transporters in the kidney and lung. Am J Physiol Renal Physiol 292: 586-592.

21. Lin CL, Wu MS, Yang CW, Huang CC, 1999. Leptospirosis associated with hypokalaemia and thick ascending limb dysfunction. Nephrol Dial Transplant 14: 193-195.

22. Knepper MA, Brooks HL, 2001. Regulation of the sodium transporters NHE3, NKCC2, and NCC in the kidney. Curr Opin Nephrol Hypertens 10: 655-659.

23. Elkjzer ML, Kwon TH, Wang W, Nielsen J, Knepper M, Froklzer J, Nielsen S, 2002. Altered expression of renal NHE3, TSC, BSC-1, and ENaC subunits in potassium-depleted rats. Am J Renal Physiol 283: 1376-1388.

24. Wang W, Know TH, Li C, Frokler J, Knepper M, Nielsen S, 2002. Reduced expression of $\mathrm{Na}-\mathrm{K}-2 \mathrm{Cl}$ cotransporter in medullary TAL I vitamin D-induced hypercalcemia in rats. Am J Physiol Renal Physiol 282: F34-F44.

25. Younes-Ibrahim M, Buffin-Meyer B, Cheval L, Burth P, CastroFaria MV, Barlet-Bas C, Marsy S, Doucet A, 1997. Na-KATPase: a molecular target for Leptospira interrogans endotoxin. Braz J Med Biol Res 30: 213-223.

26. WHO, 2003. Human Leptospirosis: Guidance for Diagnosis, Surveillance and Control. Geneva: World Health Organization.

27. Griffith ME, Hospenthal D, Murray CK, 2006. Antimicrobial therapy of leptospirosis. Curr Opin Infect Dis 19: 533-537.

28. Alexander AD, Rule PL, 1986. Penicillins, cephalosporins, and tetracyclines in treatment of hamsters with fatal leptospirosis. Antimicrob Agents Chemother 30: 835-839.

29. Truccolo J, Charavay F, Merien F, Perolat P, 2002. Quantitative PCR assay to evaluate ampicillin, ofloxacin, and doxycycline for treatment of experimental leptospirosis. Antimicrob Agents Chemother 46: 848-853.

30. Panaphut T, Domrongkitchaiporn S, Vibhagool A, Thinkamrop B, Susaengrat W, 2003. Ceftriaxone compared with sodium penicillin $\mathrm{g}$ for treatment of severe leptospirosis. Clin Infect Dis 36: 1507-1513.

31. Suputtamongkol Y, Niwattayakul K, Suttinont C, Losuwanaluk K, Limpaiboon R, Chierakul W, Wuthiekanun V, Triengrim S, Chenchittikul M, White NJ, 2004. An open, randomized, controlled trial of penicillin, doxycycline, and cefotaxime for patients with severe leptospirosis. Clin Infect Dis 39: 1417-1424.

32. Costa E, Lopes AA, Sacramento E, Costa YA, Matos ED, Lopes MB, Bina JC, 2003. Penicillin at the late stage of leptospirosis: a randomized controlled trial. Rev Inst Med Trop Sao Paulo 45: 141-145.

33. Daher E, Nogueira CB, 2000. Evaluation of penicillin therapy in patients with leptospirosis and acute renal failure. Rev Inst Med Trop Sao Paulo 42: 327-332.

34. Ko AI, Galvao RM, Ribeiro DCM, Jonhson WD, Riley LW, 1999. Urban epidemic of severe leptospirosis in Brazil. Salvador Leptospirosis Study Group. Lancet 354: 820-825.

35. Ohkawa H, Ohishi N, Yagi K, 1979. Assay for lipid peroxides in animal tissues by thiobarbituric acid reaction. Anal Biochem 95: 351-358.

36. De Brito T, Prado MJBA, Negreiros VAC, Nicastri AL, Sakata EE, Yasuda PH, Santos RT, Alves VAF, 1992. Detection of leptospiral antigens (L. interrogans serovar Copenhageni sero- 
group Icterohaemorrhagiae) by immunoelectron microscopy in the liver and kidney of experimentally infected guinea-pigs. Int $J$ Exp Pathol 73: 633-642.

37. Llama PF, Andrews P, Ecelbarger CA, Nielson S, Knepper M, 1998. Concentrating defect in experimental nephritic syndrome: altered expression of aquaporins and thick ascending limb $\mathrm{Na}^{+}$transporters. Kidney Int 54: 170-179.

38. Kim GH, Ecelbarger CA, Mitchell C, Parker RK, Wade JB, Knepper MA, 1999. Vasopressin increases Na-K-2Cl cotransporter expression in thick ascending limb of Henle's loop. Am J Physiol Renal Physiol 276: F96-103.

39. Arean VM, 1962. Studies on the pathogenesis of leptospirosis. II. A clinicopathologic evaluation of hepatic and renal function in experimental leptospiral infections. Lab Invest 11: 273-288.

40. Davila de Arriaga AJ, Rocha AS, Yasuda PH, De Brito T, 1982. Morpho-functional patterns of kidney injury in the experimental leptospirosis of the guinea-pig (L. icterohaemorrhagiae). J Pathol 138: 145-161.

41. Faine S, Kaipainen WJ, 1955. Erythromycin in experimental leptospirosis. J Infect Dis 97: 146-151.

42. Arean VM, 1962. The pathologic anatomy and pathogenesis of fatal human leptospirosis (Weil's disease). Am J Pathol 40: 393-423.

43. De Brito T, Menezes LF, Lima DM, Lourenco S, Silva AM, Alves VA, 2006. Immunohistochemical and in situ hybridization studies of the liver and kidney in human leptospirosis. Virchows Arch 448: 576-583.
44. Alt DP, Bolin CA, 1996. Preliminary evaluation of antimicrobial agents for treatment of Leptospira interrogans serovar Pomona infection in hamsters and swine. Am J Vet Res 57: 59-62.

45. Miller NG, Allen JE, Wilson RB, 1974. The pathogenesis of hemorrhage in the lung of the hamster during acute leptospirosis. Med Microbiol Immunol (Berl) 160: 269-278.

46. Segura ER, Ganoza CA, Campos K, Ricaldi JN, Torres S, Silva H, Cespedes MJ, Matthias MA, Swanvutt MA, Lopez Linan R, Gotuzzo E, Guerra H, Gilman RH, Vinetz JM, 2005. Clinical spectrum of pulmonary involvement in leptospirosis in a region of endemicity, with a quantification of leptospiral burden. Clin Infect Dis 40: 343-351.

47. Vinetz JM, 2003. A mountain out of a molehill: do we treat acute leptospirosis, and if so, with what? Clin Infect Dis 36: 15141515.

48. Burth P, Younes-Ibraim M, Santos MC, Castro-Faria Neto HC, de Castro Faria MV, 2005. Role of nonesterified unsaturated fatty acids in the pathophysiological processes of leptospiral infection. $J$ Infect Dis 191: 51-57.

49. Maciel EAP, Athanazio DA, Reis EAG, Cunha FQ, Queiroz A, Almeida D, McBride AJ, Ko AI, Reis MG, 2006. High serum nitric oxide levels in patients with severe leptospirosis. Acta Trop 100: 256-260.

50. Watt G, Jongsakul K, Ruangvirayuth R, 2002. A pilot study of $N$-acetylcysteine as adjunctive therapy for severe malaria. $Q J$ Med 95: 285-290. 